\title{
IDENTIFICATION OF CHELIDONIC ACID AND ASPARAGINE IN Ganoderma boninense- INOCULATED OIL PALM SEEDLINGS
}

\author{
SHAHIRAH BALQIS DZULKAFLI*; ABRIZAH OTHMAN*; SYAHANIM SHAHWAN*; ZAIN NURAZAH*; \\ MOHAMAD ARIF ABD MANAF*; ABU SEMAN IDRIS*; MOHD DIN AMIRUDDIN*; NOOR IDAYU TAHIR* \\ and UMI SALAMAH RAMLI*
}

\begin{abstract}
Basal stem rot (BSR) caused by Ganoderma is the major disease of oil palm and therefore, of great economic importance to the Malaysian oil palm industry. Study of the biochemical interaction between Ganoderma boninense and the oil palm was carried out using a metabolomics-based approach. The aim of this study is to identify metabolites that are responsible for classification of different types of treatments that have been applied on the oil palm seedlings namely T1, inoculation with rubber wood block (RWB) fully colonised with G. boninense PER71; T2, inoculation with uncolonised RWB and T3, oil palm seedlings without inoculation of RWB. Spear leaves from oil palm seedlings were collected and analysed using liquid chromatography-mass spectrometry (LC-MS). Principal component analysis (PCA) and partial least squares discriminant analysis (PLS-DA) were used to distinguish components of interest and potential markers, which were identified by employing a mix of accurate mass, tandem MS (MS/MS) strategies with searches in spectral libraries. Chemometric results from oil palm spear leaf LC-MS data of 48-week after infection revealed asparagine and chelidonic acid abundance in $T 1$ treated samples which was further confirmed using commercial chemical standard.
\end{abstract}

Keywords: Ganoderma boninense, Basal Stem Rot, LC-MS, inoculated oil palm.

Date received: 27 March 2018; Sent for revision: 2 April 2018; Received in final form: 5 October 2018; Accepted: 8 January 2019.

\section{INTRODUCTION}

Oil palm is of substantial economic importance due to its global use in foods, pharmaceuticals and cosmetics. Interestingly, Kushairi et al. (2017) revealed that after over 100 years oil palm transformed from being a monoculture plantation crop into the most important crop which occupies over 5.7 million hectares of land space by 2016 in Malaysia. Thus, it is imperative for both the industry players and the Malaysian government to intensify

Malaysian Palm Oil Board,

6 Persiaran Institusi, Bandar Baru Bangi,

43000 Kajang, Selangor, Malaysia.

E-mail: abi@mpob.gov.my effort in sustaining the oil palm productivity. Over the years, the oil palm industry is also under threat due to a prevailing disease known as Basal Stem Rot (BSR) caused by Ganoderma that warranted more aggressive solutions for a better disease management. BSR associated with Ganoderma is the most serious disease of oil palm in Malaysia and Indonesia (Idris et al., 2006). For over 80 years BSR has been causing severe economic losses in various regions around the world including South-east Asia (Corley and Tinker, 2003; Flood et al., 2000b).

In the early years of study, the disease was associated with old palms, however, the trend has changed (Flood et al., 2000b). Ganoderma was found to infect oil palm at the age of 12-24 months after 
planting, with increased BSR incidence on 4-5 years old palms, especially in replanted areas (Gurmit, 1991; Ariffin et al., 2000). It is almost certain that, BSR can result from root infection, followed by root contact with soil-borne inoculum or other infected roots (Cooper et al., 2011). By contrast, Paterson (2006) claimed that the disease was spread by spores rather than root. Another important study was that, Ganoderma has the ability to degrade lignin polymers in host plant (Al-Obaidi, 2016). There is some evidence to suggest that the mode of infection involves an initial apparent biotrophic phase followed by an aggressive necrotrophic stage associated with host cell wall degradation (Cooper et al., 2011). Taken together, these results also suggest that a possible final phase of infection is the formation of melanised mycelium both within host tissues and extending to the root in the form of pseudosclerotia (Cooper et al., 2011).

BSR external symptoms comprise of mottling fronds, unopened spear leaves and it is assumed that at least one-half of the basal stem has been killed by the fungus when foliar symptoms are observed (Paterson, 2007). Once the root and basal stem are affected by the pathogen, the nutrient and water supply will be restricted to reach the upper parts of the palms (Paterson, 2007). The appearance of one or more fruiting bodies and the detection of the disease lesion (dry rot) at the palm base are the two important diagnostic symptoms for confirmation of BSR in the field (Chung, 2011).

However, Lelong et al. (2010) stressed that the previous method was inefficient to diagnose plant disease. The other primary fungal infection diagnostic method was drilling into diseased material in the palm and then employing colorimetric method using ethlylenediaminetetraacetic acid (EDTA) (Natarajan et al., 1986) or a semi-selective media to cultivate Ganoderma on agar plates (Ariffin et al., 1993). Both of these methods were time-consuming and inaccurate. Overall, there were many attempts to design a reliable diagnostic technique either using molecular or non-molecular approaches, yet there was no accurate technique for detecting subclinical infections prior to the beginning of this century (Utomo and Niepold, 2000).

Preceding literatures reported contradictory opinions on the identity of Ganoderma species responsible for BSR. According to Turner (1981), at least 15 species of Ganoderma have been recorded from different parts of the world and categorised as pathogen associated with BSR. The number of species involved in the disease have not been resolved satisfactorily. In 1990, there were allegations suggesting the involvement of G. tornatum in causing BSR but until approximately five years later, there was still a debate concerning the pathogenicity of the fungus although association to the disease was made with G. miniatocinctum, G. zonatum and G. tornatum (Corley and Tinker, 2003). Previous study suggested that G. boninense has been identified as the cause of BSR in Indonesia, Malaysia and Papua New Guinea (Flood et al., 2000a). Ultimately, G. boninense, G. miniatocinctum and $G$. zonatum were later declared to be pathogenic to oil palm by an investigation on oil palm seedlings inoculated with the three species (Idris et al., 2006). A comprehensive study was also conducted on 23 Malaysian Palm Oil Board (MPOB) oil palm progenies of which, the most susceptible progeny was reported to be Deli (Elmina) dura x Deli (Elmina) dura, while partially resistant progeny was of Zaire dura x Cameroon pisifera (Idris et al., 2004).

Plants, fungi, bacteria and algae biosynthesise diverse group of chemicals of organic metabolites that contribute to their survival through signalling and defence (Baby et al., 2015). Plant host tissues often display activated defence mechanisms which produce anti-microbial compounds, enzymes and structural reinforcement that may limit pathogen growth (Dixon and Lamb, 1999). They release metabolites as defensive substances in order to counter the chemical molecules released by the pathogen that infect the plant tissues (Nusaibah et al., 2011). The response to the pathogen invoked changes in defence-related gene, protein and metabolite abundances in artificially Ganodermainoculated oil palm seedlings at different week intervals (Mohamad Arif et al., 2007).

Recent findings using metabolomics platform provide information on the relationship between phenolic compounds as potential metabolites for disease detection and oil palm preventive mechanism against BSR (Nurazah et al., 2013). Metabolomics tools had also been utilised to profile and characterise leaf metabolome with contrasting susceptibility to G. boninense (Rozali et al., 2017). A comprehensive review has summed up a total of 431 metabolites isolated and identified from various Ganoderma species using analytical methods including chromatography and mass spectrometry (Baby et al., 2015). On the other hand, the usefulness of liquid chromatography-mass spectrometry (LCMS) in characterising metabolites in a complex sample was demonstrated for oil palm spear leaf tissue (Tahir et al., 2013).

A number of researchers have reported on the metabolites produced during plant-pathogen interactions, but, information on the involvement of metabolites at early stage of infection is still lacking. This article reports on untargeted metabolomics approach to discover and identify metabolites from artificially inoculated oil palm seedlings with $G$. boninense at the early week of infection. This approach will provide information on metabolic changes involving small molecules for BSR early diagnosis. 


\section{MATERIALS AND METHOD}

\section{Chemicals}

Methanol, acetonitrile, ethanol and acetic acid of HPLC grade were purchased from Merck (Darmstadt, Germany) and purified water was prepared from Milli-Q® system (Millipore Lab, Bedford, MA, USA) water purification unit. Chelidonic acid (4-Oxo-4H-pyran-2,6-dicarboxylic acid; $98 \%$ ) and L-asparagine ( $\geq 98 \%$ ) were purchased from Sigma-Aldrich, USA.

\section{Plant Materials}

Three oil palm progenies, Deli dura x AVROS pisifera (MPOB standard cross), Deli (Elmina) dura $\mathrm{x}$ Deli (Elmina) dura (susceptible) and Zaire dura $\mathrm{x}$ Cameroon pisifera (partial resistant) were obtained from the Breeding and Quantitative Genetics Group, MPOB. The preparations of seedlings were as previously described by Syahanim et al. (2013), where the seeds were planted in polypropylene bag $(6 \times 9 \mathrm{~cm})$ and then transferred into bigger polypropylene bag $(38 \times 50 \mathrm{~cm})$ after three months. Non-sterilised 3:2:1 mixture of soil, organic matter and sand was used to mimic the field conditions. Standard nursery practice for the seedlings was carried out at the UKM-MPOB Research Station, Bangi, Selangor, Malaysia prior to artificial inoculation with $G$. boninense PER71 by root inoculation technique (Ariffin and Idris, 1990), the technique of inoculation is as shown in Figure 1. Three different treatments were carried out in this experiment with six replicates for each treatment: $\mathrm{T} 1$, seedlings treated with rubber wood block (RWB) fully colonised with G. boninense PER71; T2, treatment with uncolonised RWB (control) and T3, seedlings grown without RWB (absolute control). The RWB preparation was done according to Abdullah et al. (2001). A fruiting body was seen on top of the RWB after 48-week after inoculation and the infected root can be seen in the middle of the WB (Figure 2). Spear leaf samples, shown in Figure 3 , were collected at $0-, 12-, 24-$ and 48 -week after inoculation and the fresh samples were cleaned, dissected and frozen in liquid nitrogen before being stored at $-80^{\circ} \mathrm{C}$ for metabolite extraction. The list of samples is shown in Table 1. Figure 4 shows the inoculated 12-month old oil palm seedlings.

\section{Metabolite Extraction}

One gram of spear leaf tissue was ground in liquid nitrogen. A volume of $3 \mathrm{ml} 80 \%$ aqueous methanol was added and the mixture was vortexed for $30 \mathrm{~s}$ and then centrifuged at $4000 \mathrm{rpm}$ for $5 \mathrm{~min}$ at $25^{\circ} \mathrm{C}$. This procedure was consecutively repeated three times on the tissue sample and the supernatant were pooled together. The mixture was centrifuged for $30 \mathrm{~min}$ at $5000 \mathrm{rpm}, 25^{\circ} \mathrm{C}$ and transferred into a round bottom flask before being concentrated using rotary evaporator at $60^{\circ} \mathrm{C}$. The dried samples were reconstituted in $3 \mathrm{ml}$ of Milli-Q water and then filtered through a $0.25 \mu \mathrm{m}$ syringe filter (Sartorius AG, Goettingen, Germany) for LC-MS analysis.

\section{LC-MS Analysis}

Metabolite analysis was performed on MicrOTOF-Q ${ }^{\mathrm{TM}}$, a quadrupole/time-of-flight (Q-TOF) mass spectrometer (Bruker Daltonics $\mathrm{GmbH}$, Bremen, Germany) coupled to an Ultimate 3000 HPLC system (Thermo Scientific, USA). A total of $5 \mu$ l extract was loaded onto Acclaim ${ }^{\circledR} 120 \AA$ C18 $5 \mu \mathrm{m}, 4.6 \times 150 \mathrm{~mm}$ reversed-phase analytical

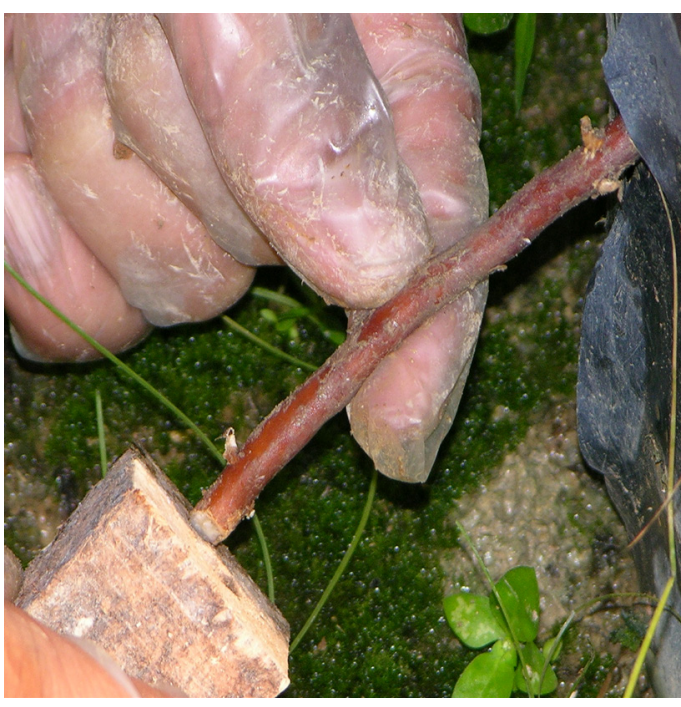

Figure 1. Artificial inoculation with G. boninense PER71 by root inoculation technique.

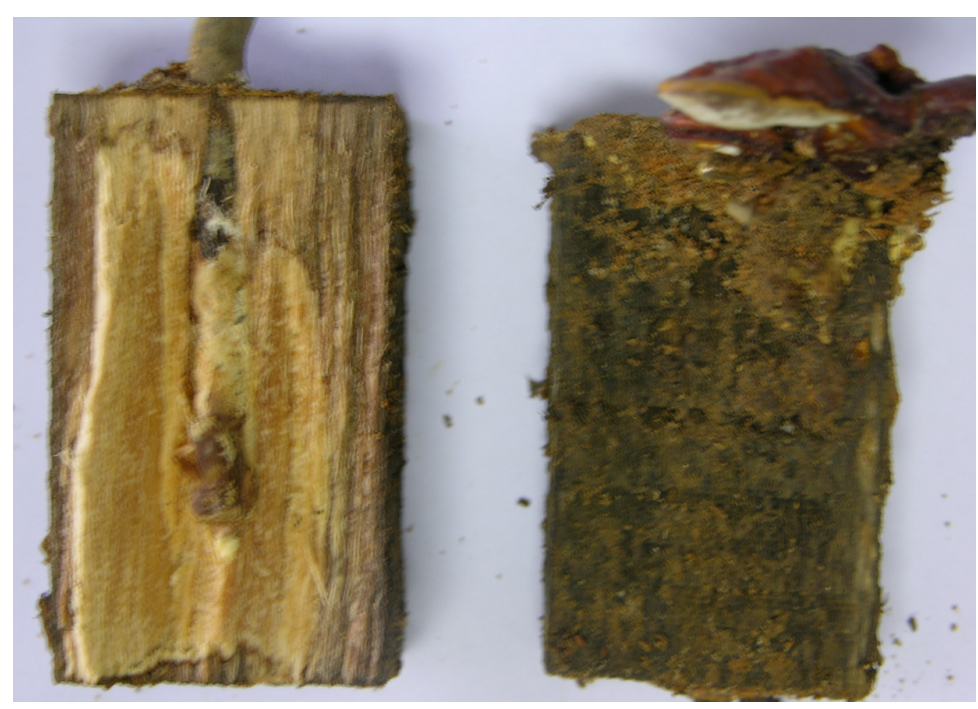

Figure 2. A cross-section of rubber wood block (RWB) contains oil palm root infected with $\mathrm{G}$. boninense PER71. The occurrences of white rot fungi are seen at the root. 


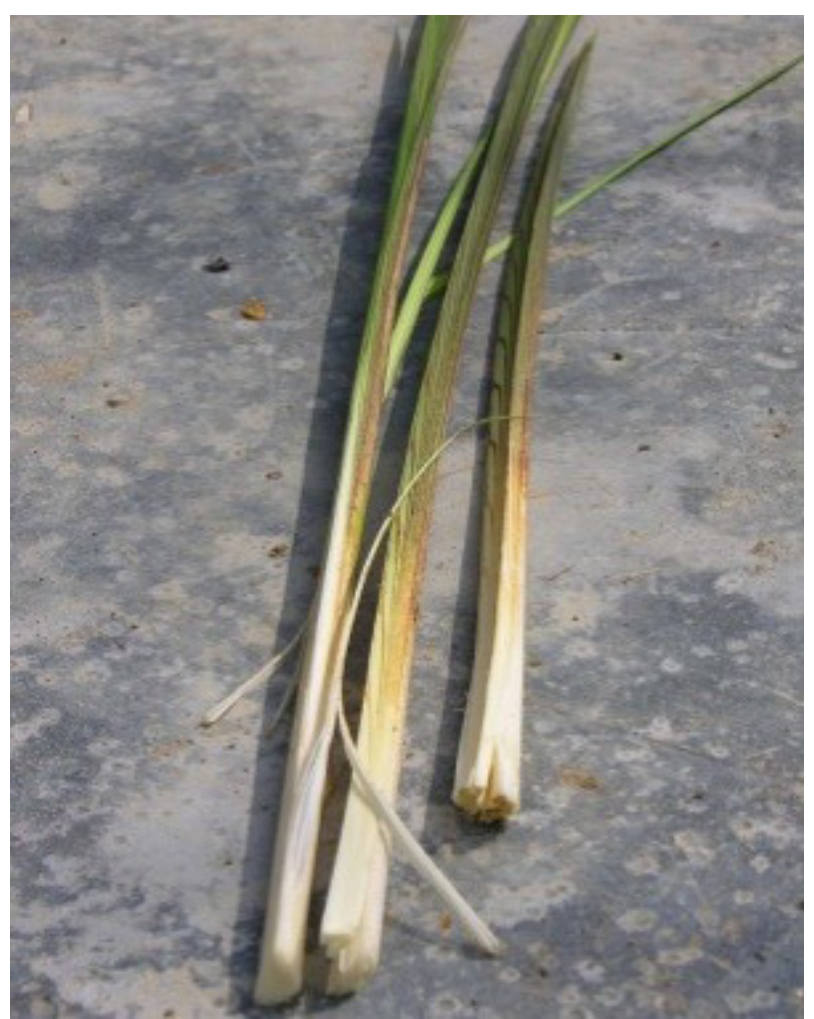

Figure 3. Spear leaf tissue samples.

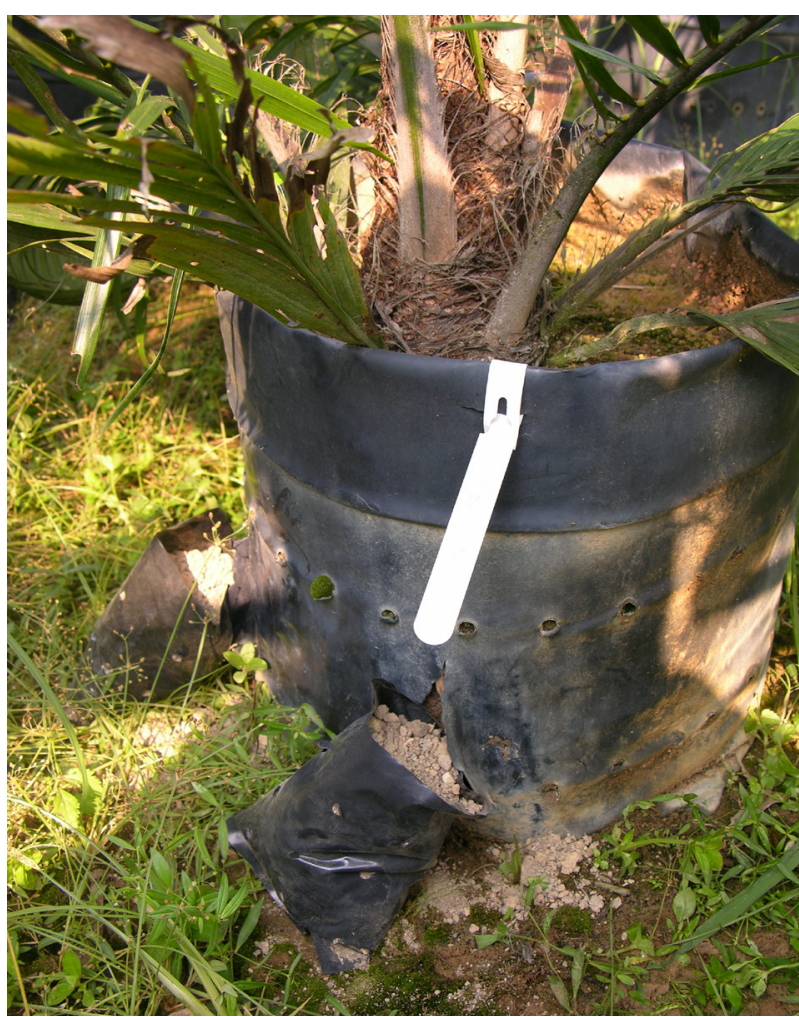

Figure 4. Twelve-month old inoculated oil palm seedling.

TABLE 1. LIST OF SAMPLES (with identification numbers)

\begin{tabular}{|c|c|c|c|c|c|c|c|c|c|c|c|c|}
\hline \multirow[t]{3}{*}{ Progenies } & \multicolumn{12}{|c|}{ Sample ID } \\
\hline & \multicolumn{4}{|c|}{ T1 } & \multicolumn{4}{|c|}{ T2 } & \multicolumn{4}{|c|}{ T3 } \\
\hline & 0 -week & 12-week & 24-week & 48-week & 0-week & 12-week & 24-week & 48-week & 0-week & 12-week & 24-week & 48-week \\
\hline \multirow{6}{*}{$\begin{array}{c}\text { Deli Dura x } \\
\text { AVROS } \\
\text { Pisifera }\end{array}$} & $1 / 1$ & $1 / 37$ & $1 / 43$ & $1 / 49$ & $2 / 1$ & $2 / 37$ & $2 / 43$ & $2 / 49$ & $3 / 1$ & $3 / 37$ & $3 / 43$ & $3 / 49$ \\
\hline & $1 / 2$ & $1 / 38$ & $1 / 44$ & $1 / 50$ & $2 / 2$ & $2 / 38$ & $2 / 44$ & $2 / 50$ & $3 / 2$ & $3 / 38$ & $3 / 44$ & $3 / 50$ \\
\hline & $1 / 3$ & $1 / 39$ & $1 / 45$ & $1 / 51$ & $2 / 3$ & $2 / 39$ & $2 / 45$ & $2 / 51$ & $3 / 3$ & $3 / 39$ & $3 / 45$ & $3 / 51$ \\
\hline & $1 / 4$ & $1 / 40$ & $1 / 46$ & $1 / 52$ & $2 / 4$ & $2 / 40$ & $2 / 46$ & $2 / 52$ & $3 / 4$ & $3 / 40$ & $3 / 46$ & $3 / 52$ \\
\hline & $1 / 5$ & $1 / 41$ & $1 / 47$ & $1 / 53$ & $2 / 5$ & $2 / 41$ & $2 / 47$ & $2 / 53$ & $3 / 5$ & $3 / 41$ & $3 / 47$ & $3 / 53$ \\
\hline & $1 / 6$ & $1 / 42$ & $1 / 48$ & $1 / 54$ & $2 / 6$ & $2 / 42$ & $2 / 48$ & $2 / 54$ & $3 / 6$ & $3 / 42$ & $3 / 48$ & $3 / 54$ \\
\hline Deli (Elmina) & $1 / 1$ & $1 / 37$ & $1 / 43$ & $1 / 49$ & $2 / 1$ & $2 / 37$ & $2 / 43$ & $2 / 49$ & $3 / 1$ & $3 / 37$ & $3 / 43$ & $3 / 49$ \\
\hline \multirow{5}{*}{$\begin{array}{l}\text { Dura x Deli } \\
\text { (Elmina) } \\
\text { Dura }\end{array}$} & $1 / 2$ & $1 / 38$ & $1 / 44$ & $1 / 50$ & $2 / 2$ & $2 / 38$ & $2 / 44$ & $2 / 50$ & $3 / 2$ & $3 / 38$ & $3 / 44$ & $3 / 50$ \\
\hline & $1 / 3$ & $1 / 39$ & $1 / 45$ & $1 / 51$ & $2 / 3$ & $2 / 39$ & $2 / 45$ & $2 / 51$ & $3 / 3$ & $3 / 39$ & $3 / 45$ & $3 / 51$ \\
\hline & $1 / 4$ & $1 / 40$ & $1 / 46$ & $1 / 52$ & $2 / 4$ & $2 / 40$ & $2 / 46$ & $2 / 52$ & $3 / 4$ & $3 / 40$ & $3 / 46$ & $3 / 52$ \\
\hline & $1 / 5$ & $1 / 41$ & $1 / 47$ & $1 / 53$ & $2 / 5$ & $2 / 41$ & $2 / 47$ & $2 / 53$ & $3 / 5$ & $3 / 41$ & $3 / 47$ & $3 / 53$ \\
\hline & $1 / 6$ & $1 / 42$ & $1 / 48$ & $1 / 54$ & $2 / 6$ & $2 / 42$ & $2 / 48$ & $2 / 54$ & $3 / 6$ & $3 / 42$ & $3 / 48$ & $3 / 54$ \\
\hline \multirow{6}{*}{$\begin{array}{l}\text { Zaire Dura x } \\
\text { Cameroon } \\
\text { Pisifera }\end{array}$} & $1 / 1$ & $1 / 37$ & $1 / 43$ & $1 / 49$ & $2 / 1$ & $2 / 37$ & $2 / 43$ & $2 / 49$ & $3 / 1$ & $3 / 37$ & $3 / 43$ & $3 / 49$ \\
\hline & $1 / 2$ & $1 / 38$ & $1 / 44$ & $1 / 50$ & $2 / 2$ & $2 / 38$ & $2 / 44$ & $2 / 50$ & $3 / 2$ & $3 / 38$ & $3 / 44$ & $3 / 50$ \\
\hline & $1 / 3$ & $1 / 39$ & $1 / 45$ & $1 / 51$ & $2 / 3$ & $2 / 39$ & $2 / 45$ & $2 / 51$ & $3 / 3$ & $3 / 39$ & $3 / 45$ & $3 / 52$ \\
\hline & $1 / 4$ & $1 / 40$ & $1 / 46$ & $1 / 52$ & $2 / 4$ & $2 / 40$ & $2 / 46$ & $2 / 52$ & $3 / 4$ & $3 / 40$ & $3 / 46$ & $3 / 52$ \\
\hline & $1 / 5$ & $1 / 41$ & $1 / 47$ & $1 / 53$ & $2 / 5$ & $2 / 41$ & $2 / 47$ & $2 / 53$ & $3 / 5$ & $3 / 41$ & $3 / 47$ & $3 / 53$ \\
\hline & $1 / 6$ & $1 / 42$ & $1 / 48$ & $1 / 54$ & $2 / 6$ & $2 / 42$ & $2 / 48$ & $2 / 54$ & $3 / 6$ & $3 / 42$ & $3 / 48$ & $3 / 54$ \\
\hline
\end{tabular}

Note: T1 - inoculation with rubber wood block fully colonised with $G$. boninense.

T2 - inoculation with uncolonised rubber wood block.

T3 - oil palm seedlings without inoculation of rubber wood block.

column (Thermo Scientific, USA). Gradient elution was performed with $\mathrm{H}_{2} \mathrm{O}$ containing $0.1 \%$ acetic acid (solvent A) and acetonitrile added with $0.125 \%$ acetic acid (solvent B). LC gradient was pre-set as follows: $0-2.5 \mathrm{~min}: 5 \% \mathrm{~B}, 2.5-59.5 \mathrm{~min}: 22 \% \mathrm{~B}$ and
59.5-60.0 min: $95 \% \mathrm{~B}$. The flow rate was $1 \mathrm{ml} \mathrm{min}^{-1}$ and the column temperature was held at $35^{\circ} \mathrm{C}$ for the analysis. The mass spectrometry source conditions were: nebuliser gas $\left(\mathrm{N}_{2}\right)$ at 3.5 bar, dry gas $\left(\mathrm{N}_{2}\right)$ at 8.0 litre $\mathrm{min}^{-1}$, dry temperature at $200^{\circ} \mathrm{C}$, capillary 
voltage at $-3500 \mathrm{~V}$ and end plate offset at $-500 \mathrm{~V}$. The MS analysis was carried out in negative ion electrospray ionisation (ESI) mode of detection and scanning range was set at $m / z$ 50-1000. Data acquisition was performed by HyStar Application version 3.2

\section{Data Analysis and Multivariate Statistics}

The raw LC-MS data was processed using DataAnalysis Version 3.4 (Bruker Daltonics, Germany) which generated a list of possible elemental formulas. Unsupervised multivariate statistics of principal component analysis (PCA) was performed on ProfileAnalysis Version 2.0 (Bruker Daltonics, Germany). The data selection and processing was done via FindMolecularFeatures (FMF) and using the time alignment parameters in the rectangular bucketing approach. The retention time range was taken from 1.5 to 55 min while the mass range was taken from 50.5 to $999.5 \mathrm{~m} / \mathrm{z}$. The data was normalised by the sum of bucket values for analysis. Supervised multivariate statistics of partial least square-discriminant analysis (PLS-DA) was performed for selected LC-MS data of Deli dura $\mathrm{x}$ AVROS pisifera (MPOB standard cross) progeny at 48-week after inoculation using a web-based tool for metabolomics data processing, statistical analysis and functional interpretation, MetaboAnalyst 3.0 (Xia and Wishart, 2016). Identification of compounds of interest present in the crude extracts was done by comparing the MS/MS fragmentation patterns and retention time $\left(t_{R}\right)$ with chemical standards.

\section{RESULTS AND DISCUSSION}

\section{Artificial Inoculation Aftermath on Seedlings}

All seedlings from Deli dura x AVROS pisifera (MPOB standard cross) progeny, inoculated with G. boninense PER71 from 0-, 12-, 24- and 48week survived. While for Deli (Elmina) dura $\mathrm{x}$ Deli (Elmina) dura (susceptible) progeny, three seedlings at 12-week after inoculation and two seedlings at 48-week after inoculation were found dead and show symptoms associated to cell death and tissue necrosis. For Zaire dura $\mathrm{x}$ Cameroon pisifera (partial resistant) progeny, colonisation progressed and caused one seedling death at 48week after inoculation, therefore suggesting BSR indeed attack much younger palm as reported previously (Mohd Zainuddin and Faridah, 2008). The base peak chromatograms from the LC-MS is shown in Figure 5.

\section{LC-MS and Chemometric Analysis of Spear Leaf Samples from Seedlings}

LC-MS metabolite fingerprint from all the analyses were statistically processed using chemometric techniques to facilitate interpretation. Unsupervised multivariate statistics, PCA is a dimensional reduction of the data sets based on their variance (Lindon et al., 2001). The PCA model containing scores and loadings plots is based on the explanatory variables and does not involve any user intervention (Trivedi and Iles, 2012). LCMS data from Deli dura x AVROS pisifera (MPOB

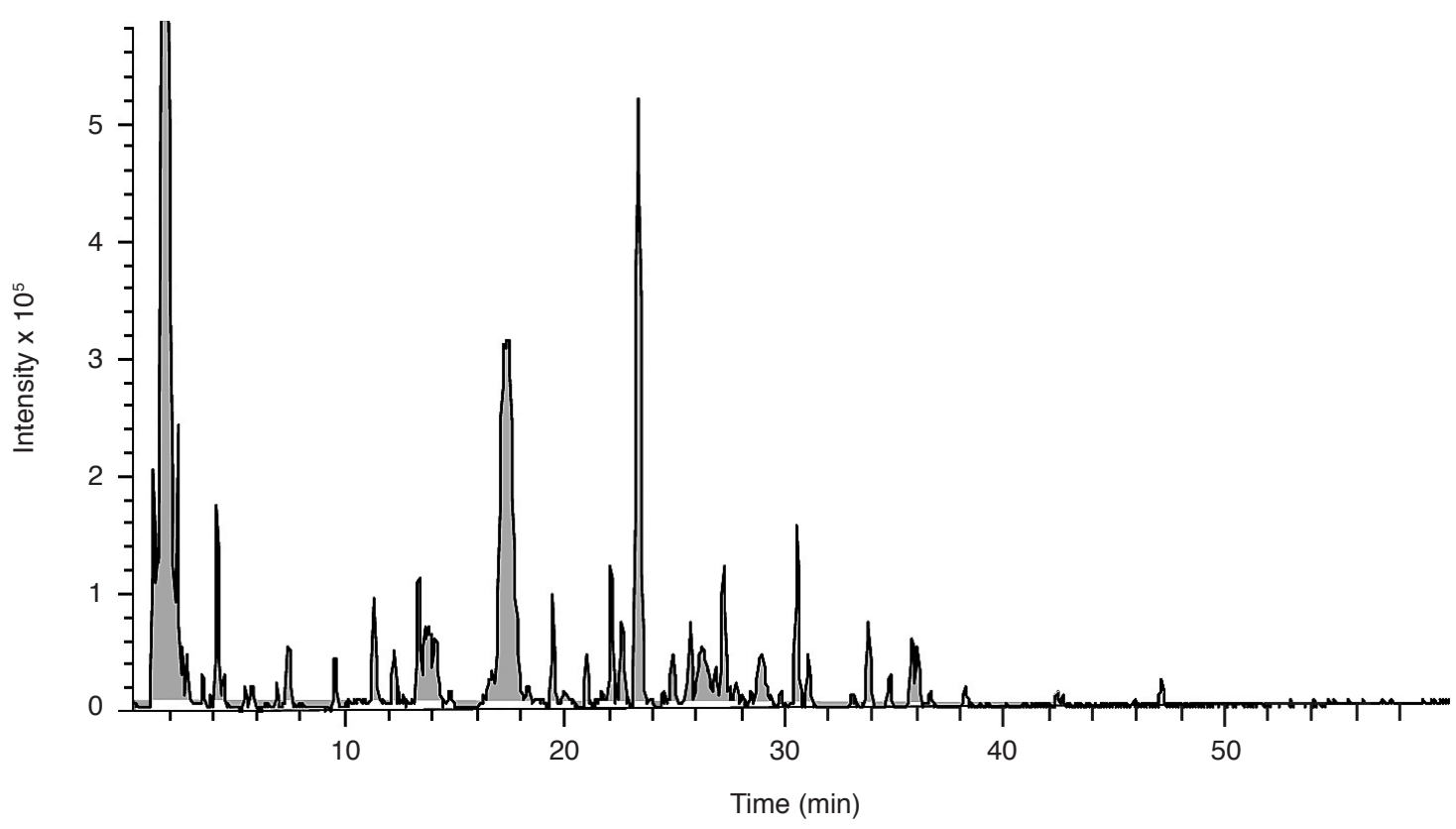

Figure 5. Liquid chromatography-mass spectrometry (LC-MS) base peak chromatogram (BPC) of oil palm spear leaf extract. 
standard cross), Deli (Elmina) dura x Deli (Elmina) dura (susceptible) and Zaire dura $\times$ Cameroon pisifera (partial resistant) progenies from 0-, 12-, 24- and 48-week after inoculation were subjected to PCA. Figure 6 ( $a$ to $d$ ) shows the scores plot for Deli dura $\mathrm{x}$ AVROS pisifera (MPOB standard cross) progeny from 0 - to 48-week after inoculation accordingly. A clear clustering pattern can be seen for T1 at 48-week after inoculation, as it is separated by the first principal component (PC) from $\mathrm{T} 2$ and $\mathrm{T} 3$, respectively (Figure $6 d$ ). The first two PC were PC1 $(21.4 \%)$ and PC2 $(34.5 \%)$, representing a total of $55.9 \%$ of the total variance in the scores plot. While for Figures $6 a$, $6 b$ and $6 c$ poor separation patterns were observed and the data points overlapped with one another. This indicates that a significant difference between treatments (T1, T2 and T3) could be observed after 48-week of G. boninense PER71 inoculation.

Figures 7 and 8 show the PCA of the LC-MS spectra of the Deli (Elmina) dura x Deli (Elmina) dura (susceptible) and Zaire dura x Cameroon pisifera (partial resistant) progenies according to the week after inoculation order, respectively. The data cannot be distinguished according to the treatment. Furthermore, several oil palm seedlings were found dead hence decreasing the number of data point for the samples. This also indicates that the different progenies have different level of incidences after

(a)

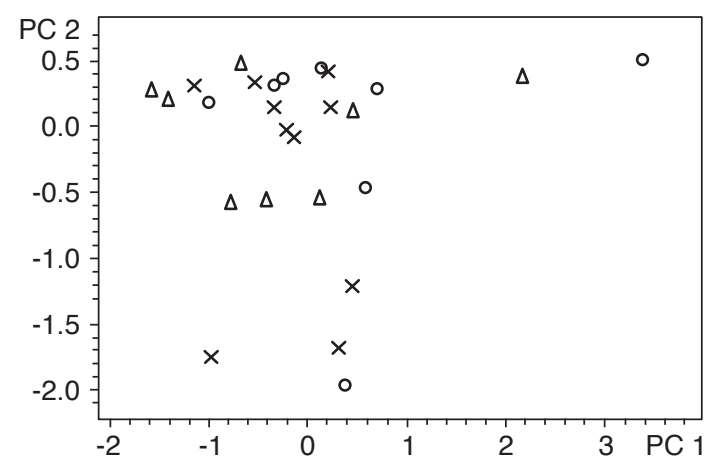

(b)

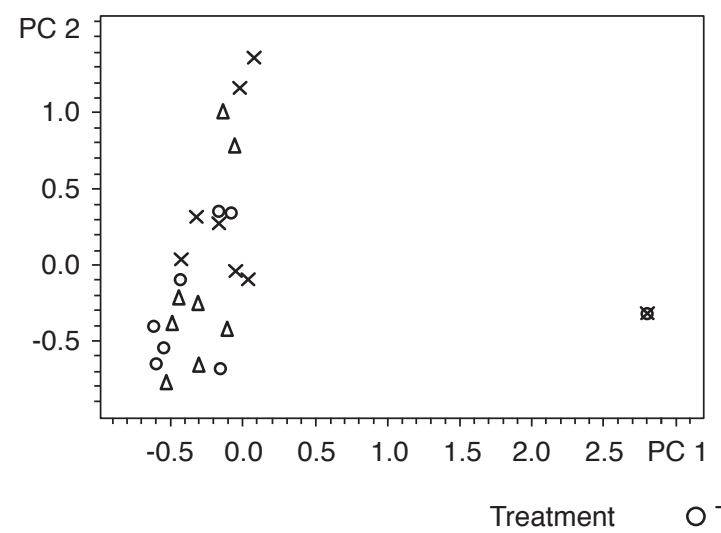

exposure to G. boninense PER71 for certain time intervals.

Clear clustering in scores plot observed in Figure $6 d$ was further analysed using comprehensive online data analysis, MetaboAnalyst (www.metaboanalyst. ca) which allowed us to focus mainly on the data from 48-week of Deli dura $x$ AVROS pisifera (MPOB standard cross). The new MetaboAnalyst PCA model restated previous result, with $\mathrm{T} 1$ distinctively separated from T2 and T3 along PC1 in the scores plot shown in Figure 9 with the variances of the first two principal components (PC) were $17.1 \%$ (PC1) and $26.3 \%$ (PC2), in total representing $43.4 \%$ of total variance in the scores plot.

As shown in Figure 10, loadings plot from the 48-week samples indicates three representative metabolite points that contributed to the clustering in the scores plot. Each three points labelled as 1, 2 and 3 in the loadings plot corresponded to $\mathrm{m} / \mathrm{z}$ $139.00,131.04$ and 182.99 respectively, are located far from the mean centre of the plot. The metabolite points that are situated far away from the origin and showed higher correlation to the treated samples from the scores plot were examined for their abundance and retention times. Based on the box plots of the three metabolites from the loadings plot, the presence of relatively higher abundance of $m / z 139.00,131.04$ and 182.99 in T1 samples may

(c)

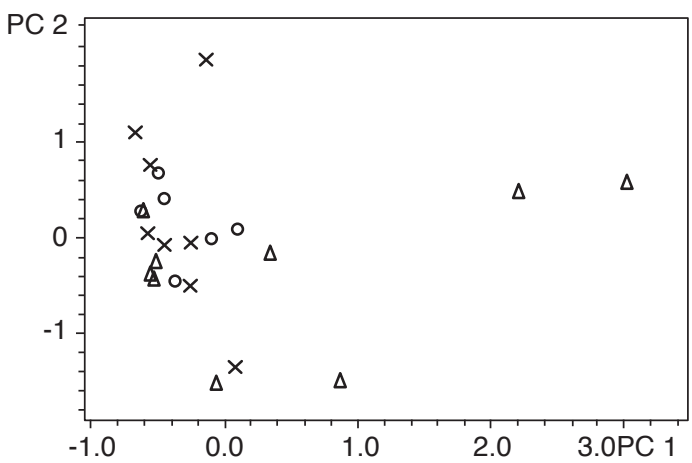

(d)

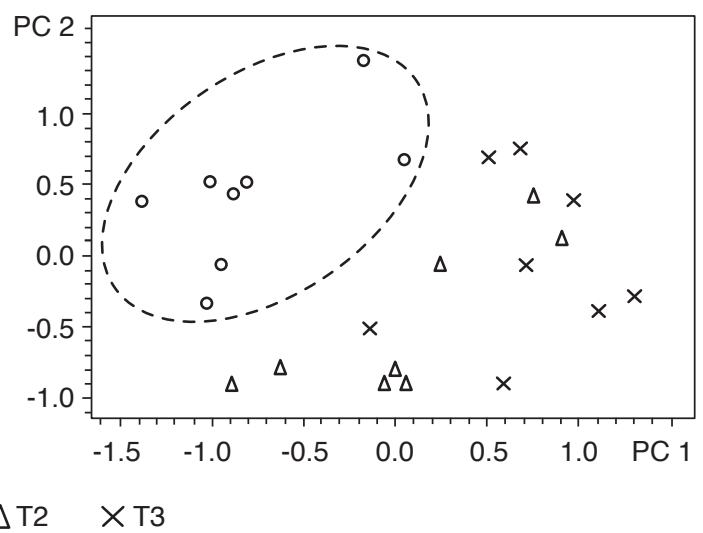

Figure 6. Principal component analysis (PCA) of liquid chromatography-mass spectrometry (LC-MS) spectra of oil palm spear leaf tissue samples of Deli dura $x$ AVROS pisifera (MPOB standard cross) after inoculation with G. boninense PER71 at: (a) 0-week, (b) 12-week, (c) 24-week and (d) 48-week. 
(a)

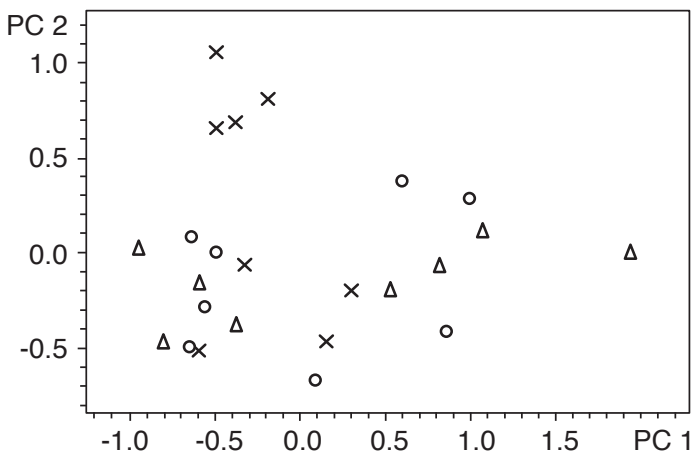

(b)

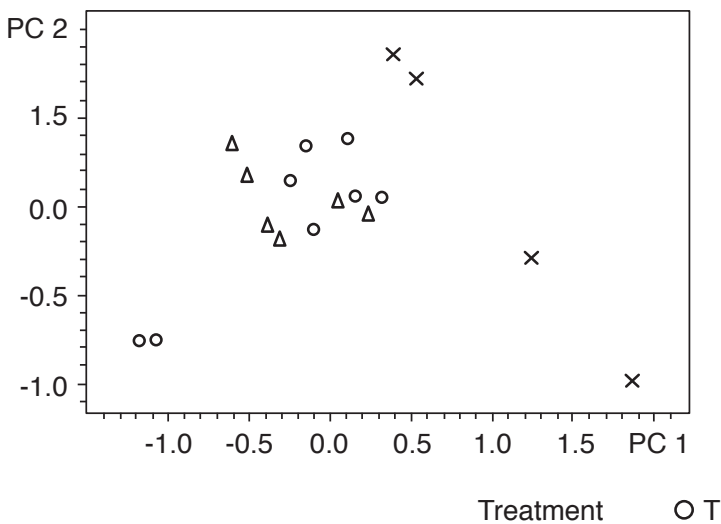

(c)

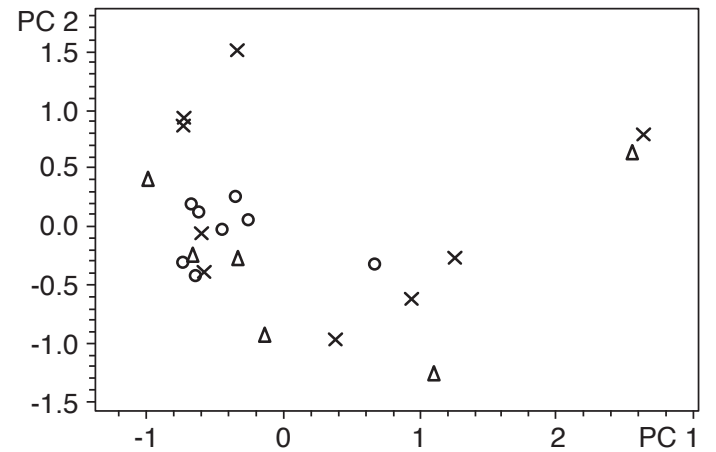

(d)

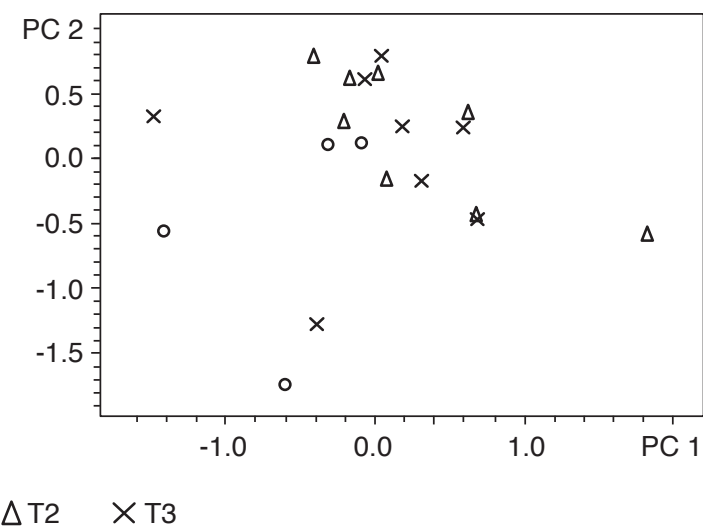

Figure 7. Principal component analysis (PCA) of liquid chromatography-mass spectrometry (LC-MS) spectra of oil palm spear leaf of Deli (Elmina) dura $x$ Deli (Elmina) dura (susceptible) after inoculation with G. boninense PER71 at: (a) 0-week, (b) 12-week, (c) 24-week, (d) 48-week.

(e)

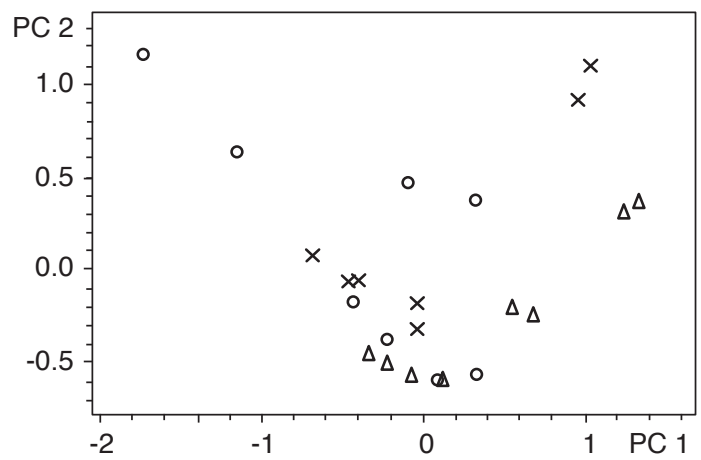

(f)

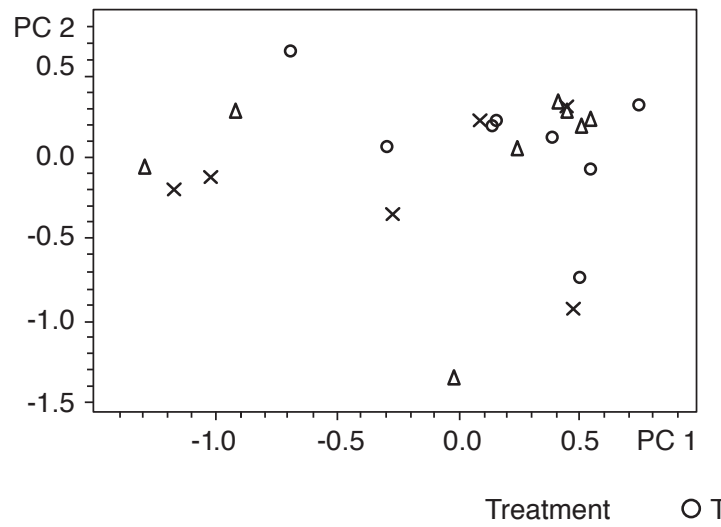

(g)

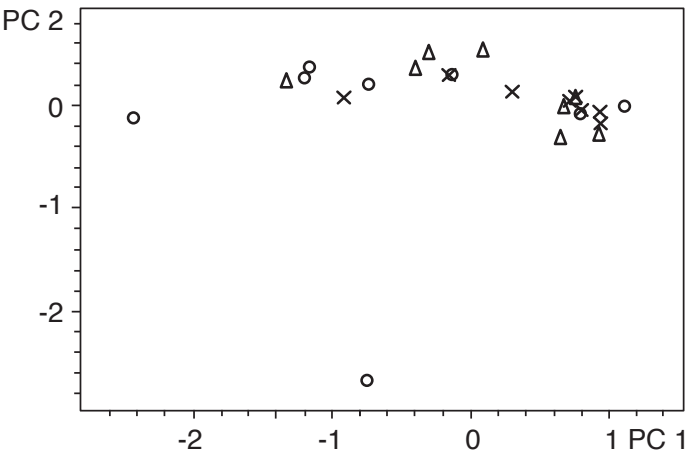

(h)

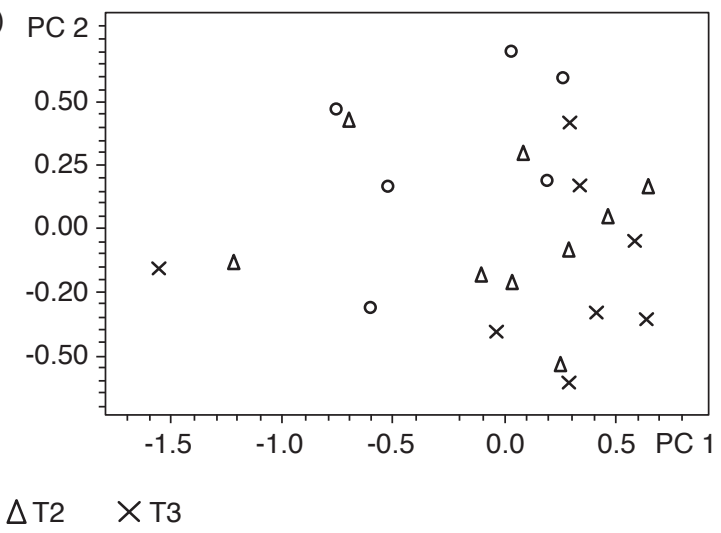

Figure 8. Principal component analysis (PCA) of liquid chromatography-mass spectrometry (LC-MS) spectra of oil palm spear leaf of Zaire dura $x$

Cameroon pisifera (partial resistant) after inoculation with G. boninense PER71 at: (e) 0-week, $(f)$ 12-week, $(g)$ 24-week and (h) 48-week. 


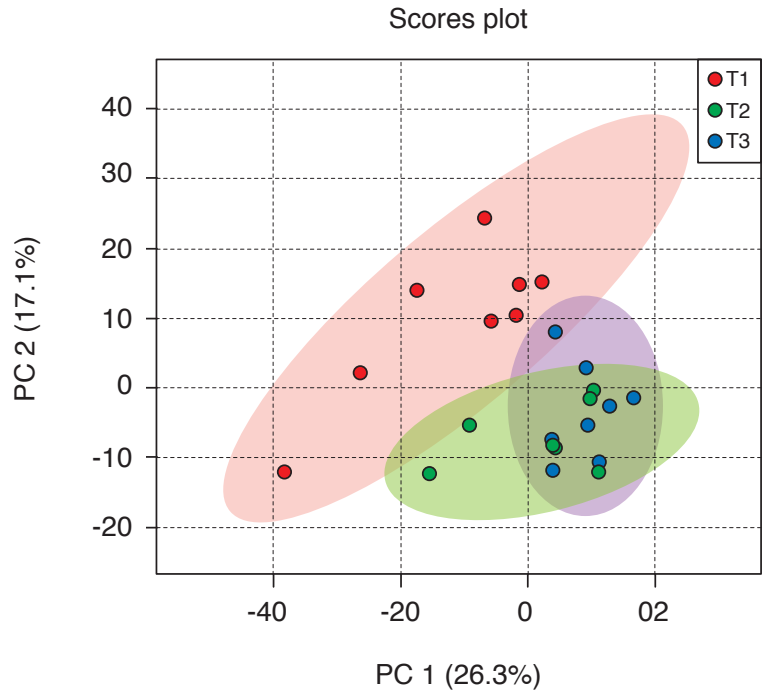

Figure 9. Principal component analysis (PCA) scores plot of liquid chromatography-mass spectrometry (LC-MS) data from oil palm Deli dura $x$ AVROS pisifera (MPOB standard cross) spear leaf tissue at 48-week of inoculation with G. boninense PER71 displayed at 95\% confidence region. intensities, or absence or presence of metabolites (Trivedi and Iles, 2012).

To assess the significance of class discrimination, a permutation test was performed. In each permutation, a PLS-DA model was built between the original variables $(X)$ and the permuted class labels $(\mathrm{Y})$ using the optimal number of components determined by cross validation for the model based on the original class assignment. PLS-DA was further analysed using analysis of variance of 10-fold Cross-Validation (CV) resulted to goodness to fit (R2) value of 0.9866 and predictive ability (Q2) with the value of 0.7964 which exceeded $50 \%$. In general, values of R2 and Q2 over 50\% are considered good for metabolic experiments (Azizan et al., 2012). Two types of permutation test statistics for measuring the class discrimination were used: i) prediction accuracy during training, and ii) separation distance which is based on the ratio of the between group sum of squares and the within group sum of squares $(\mathrm{B} / \mathrm{W})$ ratio. Both permutation tests showed statistically significance $(p<0.01)$. The PLS-DA scores
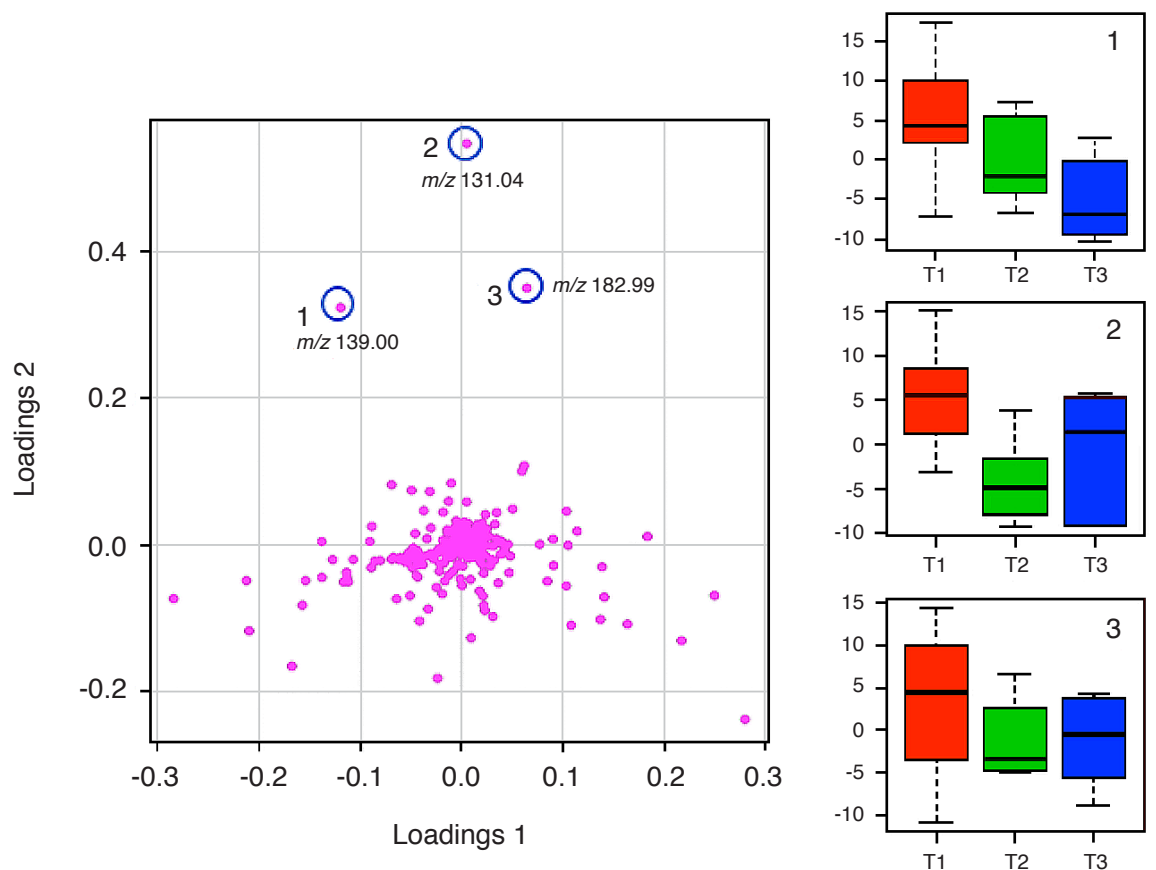

Figure 10. Principal component analysis (PCA) loadings plot of liquid chromatography-mass spectrometry (LC-MS) data from oil palm Deli dura $x$ AVROS pisifera (MPOB standard cross) spear leaf tissue at 48-week of inoculation with $\mathrm{G}$. boninense PER71 displayed $95 \%$ confidence region with box plots of three metabolite points located far from the mean centre.

explain the model and they are suggested as the influential metabolites to discriminate the $\mathrm{T} 1$ from other treatments.

PCA provides an informative first look at the dataset structure and relationship between groups. For verification and more details, analysis of partial least squares discriminant analysis (PLS-DA) can be carried out (Worley and Powers, 2013) where the groups within progenies can be predefined to observe any changes in the mean of metabolite plot showed individual clustering of samples from T1, T2 and T3 at component 1 with $40.2 \%$ of total variance of the model (Figure 11).

\section{Identification of Influential Metabolites from Chemometric Analyses}

Scores and loadings plots (Figure 12) derived from PLS-DA showed comparable bearing to that of PCA, including the relative abundances of 


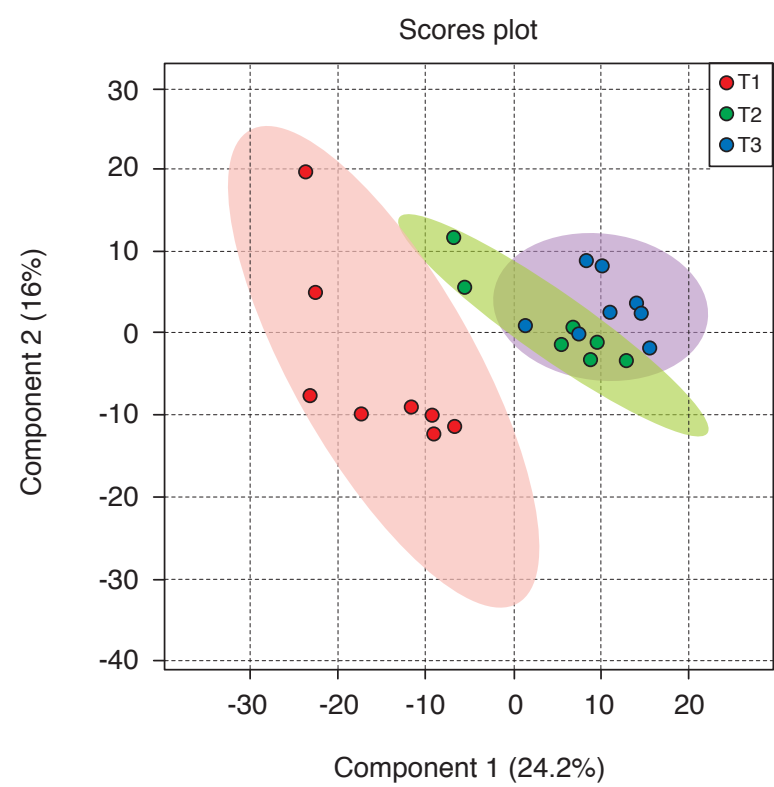

Figure 11. Partial least squares discriminant analysis (PLS-DA) scores plot of liquid chromatography-mass spectrometry (LC-MS) data from oil palm Deli dura $x$ AVROS pisifera (MPOB standard cross) spear leaf tissue at 48-week of inoculation with G. boninense PER71 displayed at 95\% confidence region.

three significant metabolites observed higher in T1 samples. The identities of the three most influential metabolites responsible for the segregation between treatments on the Deli dura x AVROS pisifera (MPOB standard cross) seedlings after 48-week inoculation was investigated using tandem MS (MS/MS). The metabolite point denoted as 1 was recorded as $\mathrm{m} / \mathrm{z}$ 139.00 with similar retention time as metabolite 3 $(\mathrm{m} / \mathrm{z}$ 182.99). Further inspection of MS and MS/MS data confirmed that this ion is a part of $\mathrm{m} / \mathrm{z} 182.99$ that was heavily fragmented during MS analysis due to its molecular structure. Similar finding and observation were recorded previously in oil palm spear leaf sample (Tahir et al., 2013). Metabolite 2 was found to be $m / z 131.04$ with accurate mass of 131.0452 and calculated molecular ion formula of $\left[\mathrm{C}_{4} \mathrm{H}_{7} \mathrm{~N}_{2} \mathrm{O}_{3}\right]^{-},[\mathrm{M}-\mathrm{H}]^{-}$. This molecular formula corresponds to that of asparagine, an amino acid. The identity of this metabolite is confirmed by their ESI-MS / MS fragment characteristics as to compare to the asparagine chemical standard (Figure 13).

Metabolite 3, m/z 182.99 which was the third metabolite point found in high abundance in T1 compared to T2 and T3 corresponds to an accurate mass of 182.9935, [M-H]- The possible molecular formula calculated for this metabolite using accurate mass is $\left[\mathrm{C}_{7} \mathrm{H}_{4} \mathrm{O}_{6}\right],[\mathrm{M}-\mathrm{H}]^{-}$. Both $\mathrm{MS}$ and MS/MS fragmentation data were employed in the metabolite identification. MS/MS analyses were performed to investigate the composition of the metabolite. Based on their ESI-MS/MS fragment characteristics in comparison to commercial standard, metabolite 3 with $\mathrm{m} / \mathrm{z} 182.99$ [M-H] $]^{-}$was identified as chelidonic acid (Figure 14). Similar retention time was observed between metabolite 3, [M-H] - and chelidonic commercial standard as shown in Figure 15. Table 2 summarises the MS / MS data and physical properties of asparagine and chelidonic acid identified in this study.
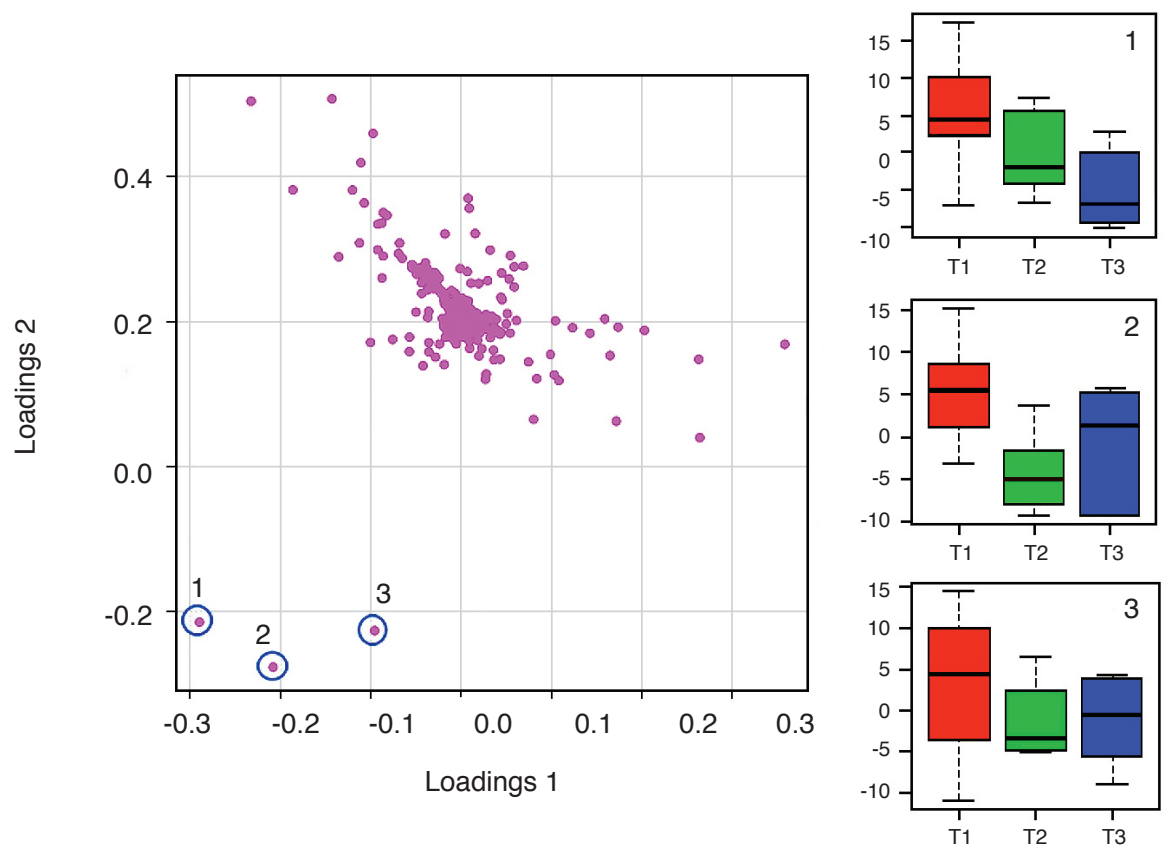

Figure 12. Partial least squares discriminant analysis (PLS-DA) loadings plot of liquid chromatography-mass spectrometry (LC-MS) data from oil palm Deli dura $x$ AVROS pisifera (MPOB standard cross) spear leaf tissue at 48-week of inoculation with G. boninense PER71 displayed 95\% confidence region with box plots of three metabolite points located far from the mean centre. 
(a)

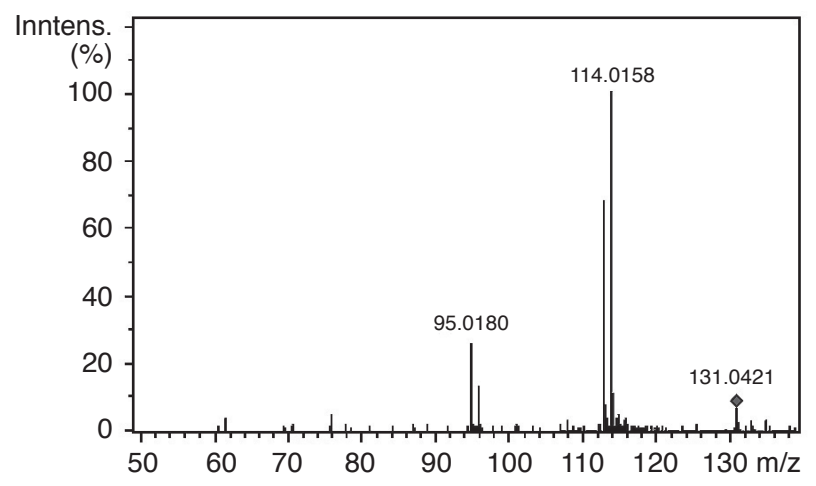

(b)

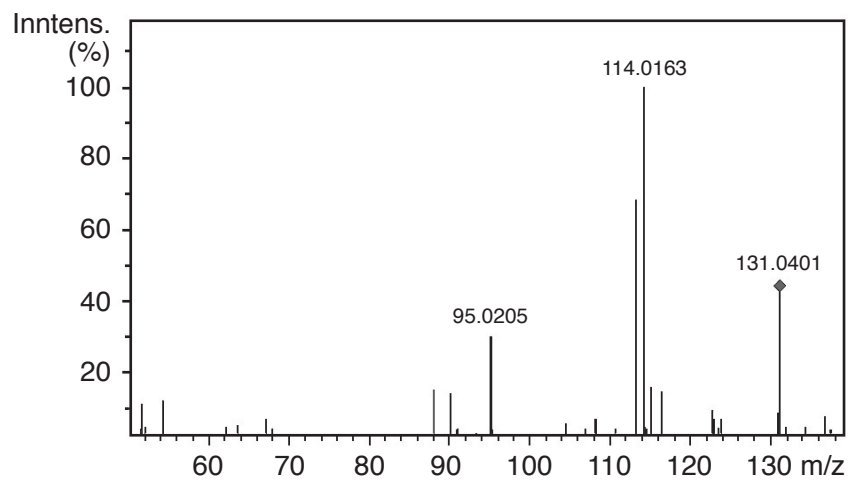

Figure 13. Similar ESI-MS/MS fragments of (a) asparagine commercial standard and (b) metabolite of m/z 131.0452 [M-H].

(a)

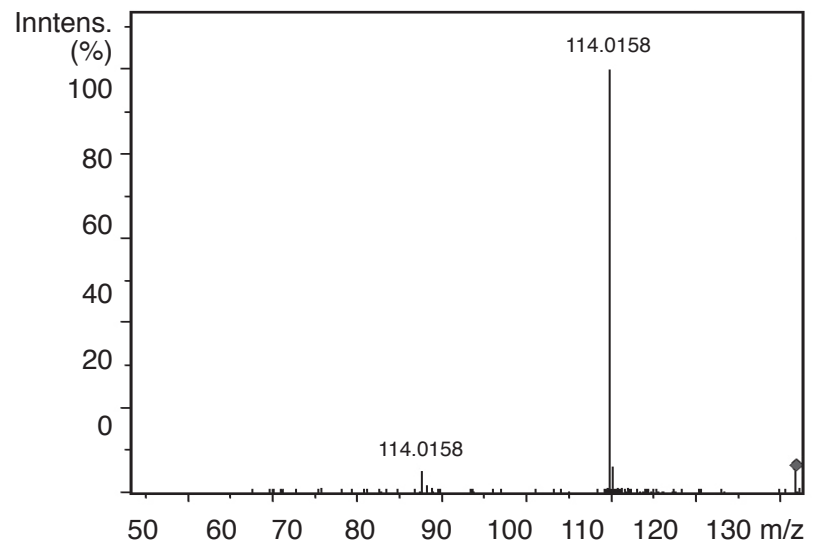

(b)

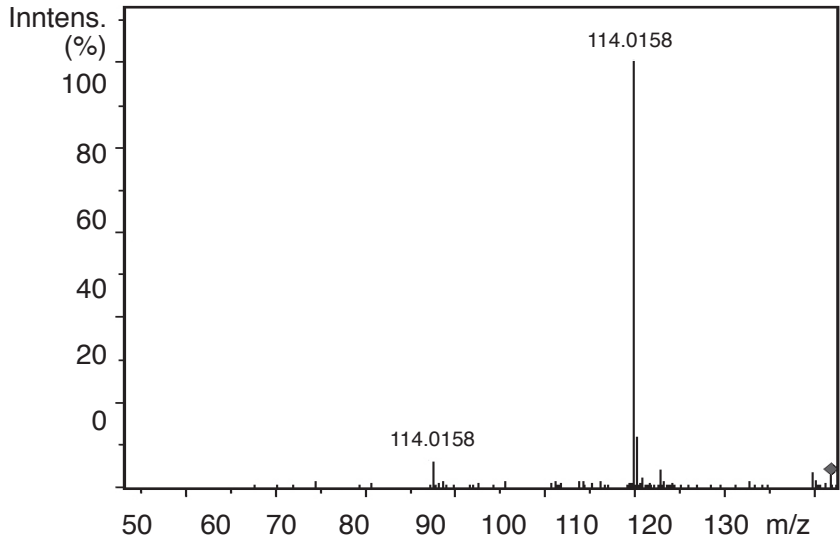

Figure 14. Similar ESI-MS/MS fragments of (a) chelidonic acid commercial standard and (b) metabolite of m/z 182.99 [M-H].

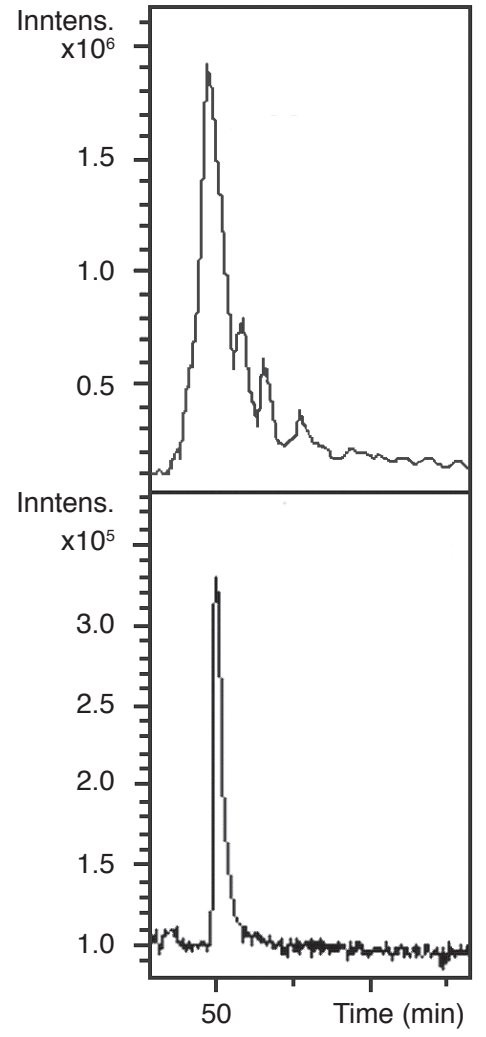

Figure 15. Similar retention time $\left(t_{R}\right)$ of commercial chelidonic acid and $\mathrm{m} / \mathrm{z}$ 182.99, $[\mathrm{M}-\mathrm{H}]^{-}$.

\section{Asparagine and Chelidonic Acid in Plants}

Both asparagine and chelidonic acid are primary metabolites found in plants. Important for plant functions and survival, primary metabolites are key metabolites that make up the plant cells with vital roles known and unknown to researchers. Amino and organic acids are among primary metabolite markers that can be signals of photosynthetic dysfunction as well as effectors of osmotic rearrangement (Arbona et al., 2013). Interestingly, the rise of asparagine content can also indicate that the plant is experiencing stress from biotic and/ or abiotic sources such as excess or shortages of minerals, water and pathogenic attack (Lea et al., 2007).

Chelidonic acid is a $\gamma$-pyrones found in various alkaloid producing plants with its role to serve as counter ions for the storage of positively charged alkaloids in the vacuolar compartment (Ramstadt, 1953). The first synthesis of the chelidonic acid was from ethyl oxalate and acetone; the process was simplified in 1904 and further improved in 1920 (Riegel and Zwilgmeyer, 1943). Chelidonic acid can be obtained from the herb celandine (Chelidonium majus) (Riegel and Zwilgmeyer, 1937). The reaction 
TABLE 2. MS/MS DATA AND PHYSICAL PROPERTIES OF ASPARAGINE AND CHELIDONIC ACID

\begin{tabular}{|c|c|c|}
\hline Compound & $\prod_{\mathrm{O}}^{\text {Asparagine }}$ & Chelidonic acid \\
\hline Chemical formula & $\mathrm{C}_{4} \mathrm{H}_{8} \mathrm{~N}_{2} \mathrm{O}_{3}$ & $\mathrm{C}_{7} \mathrm{H}_{4} \mathrm{O}_{6}$ \\
\hline Systematic International & 2-Amino-3- & 4-Oxo-4H-pyran-2,6- \\
\hline Union of Pure and Applied & carbamoylpropanoic & dicarboxylic acid \\
\hline Chemistry (IUPAC) name & acid & \\
\hline Other names & Asparagine & $\begin{array}{c}\text { Jerva acid; Jervaic acid; } \\
\text { Jervasic acid; }\end{array}$ \\
\hline Fragments & {$\left[\mathrm{M}-\mathrm{H}-\mathrm{H}_{2} \mathrm{O}\right]^{-}$} & {$\left[\mathrm{M}-\mathrm{H}-\mathrm{CO}_{2}\right]^{-}$} \\
\hline & {$\left[\mathrm{M}-\mathrm{H}-\mathrm{NH}_{3}\right]^{-}$} & {$\left[\mathrm{M}-\mathrm{H}-2 \mathrm{CO}_{2}\right]^{-}$} \\
\hline Chemical denotation & $\begin{array}{l}\text { (S)-2,4-Diamino-4- } \\
\text { oxobutanoic acid }\end{array}$ & $\begin{array}{c}\gamma \text {-Pyrone-2,6- } \\
\text { dicarboxylic acid }\end{array}$ \\
\hline Molar mass & $132.12 \mathrm{~g} \cdot \mathrm{mol}^{-1}$ & $184.10 \mathrm{~g} \cdot \mathrm{mol}^{-1}$ \\
\hline Melting point & $234^{\circ} \mathrm{C}\left(453^{\circ} \mathrm{F} ; 507 \mathrm{~K}\right)$ & $257^{\circ} \mathrm{C}\left(495^{\circ} \mathrm{F} ; 530 \mathrm{~K}\right)$ \\
\hline
\end{tabular}

Source: Cappiello et al. (2003), Choi and Kim (2013), Pubchem Compound Database, NCBI.

between chelidonic acid and alkaloids provides the apparent 'energy' of accumulation against a concentration gradient (Roberts and Wink, 1998).

Alkaloid was reported to be the least component in the total phytochemical extract from palm leaf (Yin et al., 2013) and while the presence of chelidonic acid is always correlated to alkaloids due to its trapping role, its elevated content in oil palm spear leaves from seedlings undergoing T1 could not be simply deduced according to alkaloid fate in the vacuole. Chelidonic acid abundance could be due to interim conversion in response to intra- or intercellular stimuli as it is not the ultimate end products in the cell (Robinson, 1974). This finding also resonates the potential role of organic acid or other primary metabolites in plant defence along with secondary metabolites. For instance, Nurazah et al. (2013) profiled nine metabolites from the root tissue of partially resistant and susceptible parental palms to $G$. boninense which ranged from plant sugars and phenolics derivatives. Primary metabolic pathway which is generally known as the regulator of energy to provide 'fuel of fire' and boost defence responses, has now been recognised as a source of signalling molecules to either directly or indirectly trigger defence responses (Rojas et al., 2014; Bolton, 2009). Nusaibah et al. (2011) profiled 13 sterols from the oil palm root tissue artificially infected with $G$. boninense using gas chromatography-mass spectrometry while Rozali et al. (2017) identified sugars and fatty acids from parental palms of different BSR tolerance background. The potency or anti-microbial activity of the asparagine and chelidonic acid must be further analysed. Anti-microbial compounds from plants are broadly classified into two categories: phytoanticipins and phytoalexins (Mansfield, 1999). Phytoalexins accumulate at infection sites and can inhibit the growth of fungi and bacteria while phytoanticipins are pre-existing phytoalexins that interact with a plant pathogen (Merk-Turk, 2002). Although it is possible to consider asparagine and chelidonic acid as possible markers or even plant defence metabolites against infection caused by G. boninense, inadequate information of plant and pathogen interaction from the metabolomics point of view reflects the need for more phytochemical and biological activity studies.

\section{CONCLUSION}

This study was carried out to evaluate and compare the potential of artificial inoculation technique of G. boninense PER71 on three groups of oil palm progenies to modulate pathogenic interaction at the metabolite levels using LC-MS and multivariate analysis. We assessed the data using multivariate statistics such as PCA and PLS-DA to enable visualisation and interpretation of the complex data from three different treatments. A significant clustering was observed in Deli dura x AVROS pisifera (MPOB standard cross) after 48-week of artificial inoculation with $G$. boninense PER71. This leaf sample from T1 treatment was detected with high abundance of asparagine, $\mathrm{m} / \mathrm{z} 131.04$ and chelidonic acid, $\mathrm{m} / \mathrm{z} 182.99$ compared to other 
treatments. Further characterisation using bioassayguided approach will be conducted to reveal the potential role of these metabolites in oil palm. On the other hand, the method developed in this study promises a great potential for further metabolite analysis towards an intensive search of other potential active metabolites involved in BSR early detection and biomarker discoveries.

\section{ACKNOWLEDGEMENT}

The authors would like to thank the DirectorGeneral of MPOB for permission to publish this article. Special thanks to the members of the Proteomics and Metabolomics Group, the Gene Function Group, the Breeding and Quantitative Genetics Group and the Ganoderma and Disease Research for Oil Palm (GanoDROP) Unit, MPOB for technical support and advice. Acknowledgement is also due to Dr Nurniwalis Abdul Wahab and Nor Hanin Ayub for their valuable assistance.

\section{REFERENCES}

Abdullah, F; Jayanthi, N; Ilias, G N M and Nelson, M (2001). Properties of substrate inocula and plant host in disease establishment by G. boninense and G. philippi. Proc. of the PIPOC 2001 International Palm Oil Congress. MPOB, Bangi. p. 618-623.

Al-Obaidi, J R (2016). Proteomics of edible mushrooms: A mini-review. Electrophoresis, 37: 1257-1263.

Arbona, V; Manzi, M; De Ollas, C and GomezCadenas, A (2013). Metabolomics as a tool to investigate abiotic stress tolerance in plant. Int. J. Mol. Sci, 14: 4885-4911.

Ariffin, D; Idris, A S and Singh, G (2000). Status of Ganoderma in oil palm. Ganoderma Diseases of Perennial Crops (Flood, J; Bridge, PD and Holdermess, M eds.). CABI Publishing, UK. p. 49-68.

Ariffin, D; Idris, A S and Khairudin, H (1993). Confirmation of Ganoderma infected palm by drilling technique. Proc. of the PORIM International Palm Oil Congress. PORIM, Bangi. p. 735-738.

Ariffin, D and Idris, A S (1990). Artificial inoculation of oil palm seedlings with Ganoderma boninense. Paper presented at the Joint Agronomy/Breeding/ Pathology Meeting. PORIM, Bangi.

Azizan, K A; Baharum, S N; Ressom, H W and Noor, N M (2012). GC-MS analysis and PLS-DA of the trimethyl silyl-derivatization techniques. Am. J. Appl Sci, 9 (7): 1124-1136.
Baby, S; Johnson, A J and Govindan, B (2015). Secondary metabolites from Ganoderma. Phytochemistry, 114: 66-101.

Bolton, M D (2009). Primary metabolism and plant defence - Fuel for the fire. Mol Plant Microbe Interact., 22 (5): 487-497.

Cappiello, A; De Simoni, E; Fiorucci, C; Mangani, F; Palma, P; Trufelli, H; Decesari, M; FACchini, C and Fuzzi, S (2003). Molecular characterization of the water-soluble organic compounds in fog water by EIMS/MS. Environ. Sci. Technol., 37: 1229-1240.

Choi, S and Kim, O (2013). Fragmentation of deprotonated amino acids in atmospheric pressure chemical ionization. International J. Mass Spectrometry, 338: 17-22.

Chung, G F (2011). Management of Ganoderma diseases in oil palm plantations. The Planter, 87(1022): 325-339.

Cooper, R M; Flood, J and Rees, R (2011). Ganoderma boninense in oil palm plantations: Current thinking on epidemiology, resistance and pathology. The Planter, 87: 515-526.

Corley, R H V and Tinker, P B (2003). The Oil Palm. Blackwell Publishing, Oxford.

Dixon, R A and Lamb, C J (1999). Molecular communication in interactions between plants and microbial pathogens. Annu. Rev. Plant Physiol. Plant Mol. Biol., 41: 339-367.

Flood, J; Bridge, P D and Holderness, M (2000a). Ganoderma Diseases of perennial crops. CABI Publishing, Wallingford, United Kingdom.

Flood, J; Husan, Y; Turner, P D and O'Grady, E B (2000b). The spread of Ganoderma from infective sources in the field and its implications for management of the disease in oil palm. Ganoderma Diseases of Perennial Crops (Flood, J; Bridge, P D and Holdermess, M eds.). CABI Publishing, Wallingford, United Kingdom. p. 101-112.

Gurmit, S (1991). Ganoderma - The scourge of oil palm in the coastal area. Proc. of the Ganoderma Workshop, PORIM, Bangi. p. 7-35.

Idris, A S; Kushairi, A; Ariffin, D and Basri, M $W$ (2006). Technique for inoculation of oil palm geminated seeds with Ganoderma. MPOB Information Series No. 314.

Idris, A S; Kushairi, A; Ismail, S and Ariffin, D (2004). Selection for partial resistance in oil palm progenies 
to Ganoderma basal stem rot. J. Oil Palm Res. Vol. 16: 12-18.

Kushairi, A; Singh, R and Ong-Abdullah, M (2017). The oil palm industry in Malaysia: Thriving with transformative technologies. J. Oil Palm Res. Vol. 29 (4): 431-439.

Lea, P J; Sodek, L; Parry, M A J; Shewry, P R and Halford, N G (2007). Asparagine in plants. Ann. Appl. Biol., 150: 1-26.

Lelong, C C; Roger, J-M; Bregand, S; Dubertret, F; Lanore, M; Sitorus, N, Raharjo, D and Caliman, J-P (2010). Evaluation of oil-palm fungal disease infestation with canopy hyperspectral reflectance data. Sensors, 10 (1): 734-747.

Lindon, J C; Holmes, E and Nicholson, J K (2001). Pattern recognition methods and applications in biomedical magnetic resonance. Prog. Nuc. Magn. Reson. Spectrosc., 39:1-40.

Mansfield, J W (1999). Antimicrobial compounds and resistance: The role of phytoalexins and antianticipins. Mechanisms of Resistance to Plant Diseases (Slurenko, A J; Fraser, R S S and Van Loon, L C eds.). Kluwer, Amsterdam.

Merk-Turk, F (2002). Phytoalexins: Defence or just response to stress? J. Cell Mol. Biol., 1: 1-6.

Mohamad Arif, A M; Abrizah, O; Zetty Norhana, B Y; Syahanim, S; Idris, A S; Mohd Din, A and Ravigadevi, S (2007). Molecular and biochemical approaches to understanding oil palm-Ganoderma interactions. Proc. of the 2007 PIPOC International Palm Oil Congress. p. 228-246.

Mohd Zainuddin, N A I and Faridah, A (2008). Disease suppression in Ganoderma-infected oil palm seedlings treated with Trichoderma harzianum. Plant Prot. Sci., 44 (3): 101-107.

Natarajan, S; Bhaskaran, $\mathrm{R}$ and Shanmugan, N (1986). Preliminary studies to develop techniques for early detection of Thanjavur wilt in coconut. Indian Coconut J., 17 (3): 3-6.

Nurazah, Z; Idris, A S; Kushairi, A and Ramli, U S (2013). Metabolite profiling of oil palm towards understanding Basal Stem Rot (BSR) disease. J. Oil Palm Res. Vol. 25 (1): 58-71.

Nusaibah, S A; Siti Nor Akmar, A; Mohamad Pauzi, Z; Idris, A S and Sariah, M (2011). Detection of phytosterols in Ganoderma boninense - Infected oil palm seedlings through GC-MS analysis. J. Oil Palm Res. Vol. 23: 1069-1077.
Paterson, R R M (2007). Ganoderma disease of oil palm - A white rot perspective necessary for integrated control. Crop Prot., 26: 1369-1376.

Paterson, R R M (2006). Ganoderma - A therapeutic fungal biofactory. Phytochem., 67: 1985-2001.

Ramstadt, E (1953). The presence of distribution of chelidonic acid in some plant families. Helv. Physiol. Pharmacol. Acta, 28: 45-57.

Riegel, E R and Zwilgmeyer, F (1943). Chelidonic acid. Organic Syntheses Coll., 2: 126.

Riegel, E R and Zwilgmeyer, F (1937). Chelidonic acid. Organic Synthesis Coll., 17: 40.

Roberts, M F and Wink, M (1998). Alkaloids: Biochemistry, Ecology and Medicinal Applications. Plenum Press, New York, USA.

Robinson, T (1974). Metabolism and function of alkaloids in plants. Science, 184: 430-435.

Rojas, C M; Senthil-Kumar, M; Tzin, V and Mysore, K S (2014). Regulation of primary plant metabolism during plant-pathogen interactions and its contribution to plant defence. Front. Plant Sci., 5 (17): 1-12.

Rozali, N L; Yarmo, M A; Idris, A S; Kushairi, A and Ramli, U S (2017). Metabolomics differentiation of oil palm (Elaeis guineensis Jacq.) spear leaf with contrasting susceptibility to Ganoderma boninense. Plant Omics, 10 (02): 45-52.

Syahanim, S; Abrizah, O; Mohamad Arif, A M; Idris, A S and Mohd Din, A (2013). Identification of differentially expressed proteins in oil palm seedlings artificially infected with Ganoderma: A proteomics approach. J. Oil Palm Res. Vol. 25: 298304.

Tahir, N I; Shaari, K; Abas, F; Ahmad Parveez, G K; Hashim, A T and Ramli, U S (2013). Identification of oil palm (Elaeis guineensis) spear leaf metabolites using mass spectrometry and neutral loss analysis. J. Oil Palm Res. Vol. 25 (1): 72-83.

Trivedi, D K and Iles, R K (2012). The application of SIMCA P+ in shotgun metabolomics analysis of ZIC HILIC MS spectra of human urine experience with the shimadzu IT TOF and profiling solutions data extraction software. J. Chromat. Separation Techniq., 3: 6.

Turner, P D (1981). Oil Palm Disease and Disorders. The Incorporated Society of Planters. Oxford University Press, Kuala Lumpur. p. 280. 
Utomo, C and Niepold, F (2000). Development of diagnostic methods for detecting Ganodermainfected oil palms. J. Phytopathol. 148 (9-10): 507514.

Worley, B and Powers, R (2013). PCA as a partial indicator of OPLS-DA model reliability. Curr. Metabolomics, 4(2): 97-103.
Xia, J and Wishart, D S (2016). Using MetaboAnalyst 3.0 for comprehensive metabolomics data analysis. Curr. Protoc. Bioinformatics, 55: 14.10.1-14.10.91.

Yin, N S; Abdullah, S and Phin, C K (2013). Phytochemical constituents from leaves of Elaeis guineensis and their antioxidant and antimicrobial activity. Int. J. Pharm. Pharm. Sci., 5 (4): 137-140.

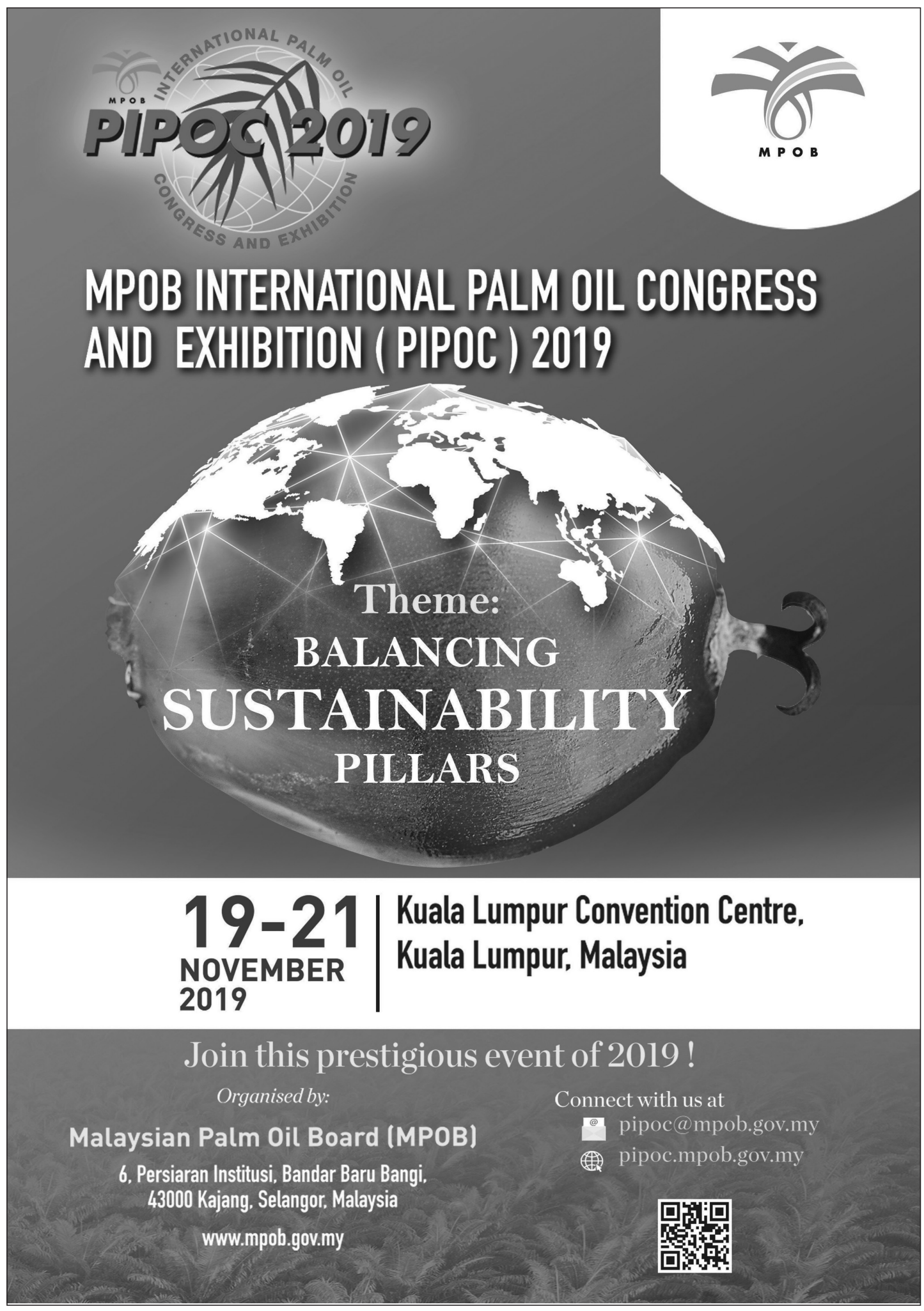

